\title{
EDUCAÇÃO MUSICAL \\ NA ESCOLA: VALORIZAR O \\ HUMANO EM CADA UM DE NÓS
}

\author{
Olavo Pereira Soares ${ }^{1}$ \\ Rosimeire Bragança Cerveira ${ }^{I}$ \\ Suely Amaral $\mathrm{Mello}^{2}$ (1)
}

\begin{abstract}
Resumo: O presente artigo analisou dados de pesquisa desenvolvida com alunos atendidos por um programa de escola pública em tempo integral, $90 \%$ desses em situaçáo de vulnerabilidade social. Os dados foram coletados pela professora de música que realizava pesquisa acadêmica sobre a temática. $\mathrm{O}$ objetivo foi demonstrar que a educação musical na escola pode adotar uma perspectiva humanizadora, quando educar em música significa possibilitar a aprendizagem da música como fenômeno histórico, social e cultural, passível de ser compreendida e produzida por todos os seres humanos.
\end{abstract}

Palavras-chave: Educação musical. Humanização. Perspectiva histórico-cultural.

\section{Music education in school: valuing the human in each of us}

Abstract: The article analyzes research data developed with students attended by a full-time public-school program $90 \%$ of them in situations of social vulnerability. The data was

\footnotetext{
${ }^{1}$ Universidade Federal de Alfenas, Programa de Pós-Graduação em Educação - Alfenas (MG), Brasil. E-mails: olavopereirasoares@gmail.com; rosimeirecerveira@yahoo.com.br ${ }^{2}$ Universidade Estadual Paulista "Júlio de Mesquita Filho", Programa de Pós-Graduação em Educação - Marília (SP), Brasil. E-mail: suepedro@terra.com.br
}

DOI: 10.1590/CC0101-32622019213043 
collected by the music teacher who carried out an academic research on the subject. This work's goal is to demonstrate that music education in school can bring a humanizing perspective, when educating in music means to enable the learning of music as a historical, social and cultural phenomenon, that can be understood and produced by all human beings.

Keywords: Musical education. Humanization. Culturalhistorical approach.

\section{INTRODUÇÃO}

A

educaçáo musical que recebemos na escola, cada um de nós, autores, foi um tanto diversa. Para quem nasceu na década de 1950, o encontro com a música na escola aconteceu no que corresponde ao atual ensino fundamental II. Os alunos solfejavam e participavam do canto orfeônico: todos supostamente estáticos cantando o cancioneiro popular durante quatro anos. Dessa experiência vivida ficou apenas a lembrança de uma apresentação pública com roupas esquisitas e lanchinho no intervalo. Nenhum novo prazer ou necessidade foi criado nos alunos, nenhuma informação potente que abrisse para os alunos uma nova linguagem de expressão. A educação musical era concebida como o ensino de técnicas desconectadas das interaçôes e produçóes musicais dos sujeitos que frequentavam a escola.

Para quem nasceu na década de 1960, nấo houve sequer o ensino das técnicas. A universalização do acesso à escola pública foi concomitante à crescente desvalorização do papel da educação escolar nos processos de inserçấo dos alunos na história e cultura da sociedade brasileira. Não havia mais resquícios do projeto de educação musical elaborado e difundido por Villa Lobos. Nos anos 1970, a força da prescrição reduzia a educação musical às aulas de educação artística. Desde então, a música paulatinamente perdeu espaço nos currículos e nos projetos das políticas públicas.

Nas últimas décadas, a educaçáo musical na escola se circunscreveu a poucos projetos realizados em escolas públicas e particulares. 
Em alguns casos, a música é parte do currículo da educação infantil e do ensino fundamental, não como conhecimento específico, mas como conteúdo da disciplina de artes. Nas escolas públicas, a música permanece fora do currículo da escola regular. Quando ocorrem, as aulas de música fazem parte de projetos relacionados à escola de tempo integral, na qual são oferecidas oficinas de algumas áreas do conhecimento, entre elas, a música.

Apesar da legislação que dispóe sobre a obrigatoriedade da educação musical na educação escolar, a música que permanece na escola ainda é considerada atividade lúdica ou recurso didático. Docentes usam a música para exemplificar conteúdos ou para "facilitar" o acesso a determinados conceitos. Gestores utilizam a música nas festas e eventos escolares para "envolver" a comunidade. Enfim, o que temos verificado é que, seja como elemento lúdico ou suporte didático, a música na escola se distancia dos processos de educação musical, pois se por um lado não envolve e não valoriza a audição dos alunos, não educa sensibilidades e nem cria novas necessidades humanizadoras, por outro não auxilia os alunos a se perceberem como sujeitos capazes de produzir música.

Nas linhas que se seguem defendemos uma educação musical que seja humana e humanizadora, que constitua, desenvolva e valorize capacidades de apropriação do mundo pelo ser humano: por exemplo, a imaginação como elemento para o aprendizado e a respectiva transformação desse aprendizado em conhecimento e desenvolvimento humano. Neste texto fazemos essa discussão considerando os processos de educação que apontam como desafio para a escola a constituição de uma nova cultura escolar. Isso envolve as concepçóes de criança e de aluno que, de um modo geral, percebemos presentes na escola e as especificidades para pensar a música nos processos de ensino e aprendizagem. Para isso, apresentamos e analisamos uma experiência didática com a educação musical referenciada na perspectiva da educação desenvolvente.

\section{A MÚSICA COMO FONTE DE QUALIDADES HUMANAS}

Tomamos como pressuposto teórico e metodológico da experiência realizada o papel essencial da escola no processo de humanização, uma vez que é na escola que as objetivaçóes da esfera da vida não coti- 
diana podem ser apresentadas à maioria das crianças em nossa sociedade, a compreensão da cultura como fonte das qualidades humanas e a compreensão da escola como lugar da cultura mais elaborada.

O conjunto de conhecimentos advindos de diferentes campos da ciência - das neurociências, da psicologia, da pedagogia, da antropologia, da sociologia - tem demonstrado amplamente que as qualidades humanas são produzidas pela atividade humana ao longo da história. Como afirma Marx,

Cada uma de suas [do ser humano] relaçóes humanas com o mundo, a visão, a audição, o olfato, o paladar, o tato, o pensamento, a contemplaçáo, o sentimento, a vontade, a atividade, o amor, em resumo, todos os órgãos da sua individualidade que, na sua forma, são imediatamente órgãos sociais, são, no seu comportamento objetivo ou na sua relaçáo com o objeto, a apropriaçáo deste, a apropriação da realidade humana. (MARX, 1962 apud LEONTIEV, 1978b, p. 267-268).

Ou seja, os cinco sentidos e também os sentidos práticos e os intelectuais - as qualidades humanas ou os órgãos da individualidade humana - são frutos da experiência de cada um. Nas palavras de Leontiev "o que a natureza lhe dá quando nasce não basta para viver em sociedade. É-lhe ainda preciso adquirir o que foi alcançado no decurso do desenvolvimento histórico da sociedade humana" (LEONTIEV, 1978b, p. 267).

Somos, portanto, resultado de nossas vivências, o que significa dizer, conforme Vygotsky (2010), que as particularidades do sujeito que aprende são essenciais na aquisição das qualidades humanas constituídas ao longo do desenvolvimento da sociedade:

A vivência é uma unidade na qual, por um lado, de modo indivisivel, o meio, aquilo que se vivencia está representado - a vivência sempre se liga àquilo que está localizado fora da pessoa - e, por outro lado, está representado como eu vivencio isso (VYGOTSKY, 2010, p. 686, grifos do original). 
Em outras palavras, a criança que aprende é sujeito agente ativo e criador no processo de aprender: aprende com o corpo, a mente e as emoções, aprende com seu ser inteiro. Essa unidade cognição/afeto implica que nossa intenção na organização do processo educativo não deve contemplar apenas os objetos da cultura que apresentamos às crianças, mas também a forma como fazemos isso. A criança aprende quando interessada, afetada pelos objetos da cultura que apresentamos. E seu interesse - afeto, vontade, necessidade, desejo — se forma também nas relaçóes que possibilitamos que as crianças estabeleçam com a cultura. $\mathrm{E}$, nesse sentido, somos também responsáveis por possibilitar a formação de novos afetos, desejos e necessidades nas crianças e alunos.

Abordar o ensino da música numa perspectiva humanizadora e desenvolvente (DAVÍDOV, 1988) envolve as clássicas questóes: Porque ensinar música na escola? Com que perspectiva? E como ensinar música de acordo com a perspectiva adotada?

Responder a essas questóes envolve compreender a afirmação de Vygotsky de que a cultura é fonte das qualidades humanas por considerar que, com cada objeto criado ao longo da história, foram criadas também as capacidades necessárias ao seu uso e que passam a fazer parte do objeto.

No entanto, como afirma Leontiev (1978a), essas qualidades não estão dadas, mas apenas postas nesses objetos. Para se apropriar delas é preciso reproduzir com os objetos sua funçáo adequada, ou seja, a função para a qual o objeto foi criado. E essa função social dos objetos, aprendemos nas relaçóes sociais. $\mathrm{Na}$ escola, o/a professor/a é elemento central nessas relações que humanizam as esferas motoras e intelectuais das novas geraçóes.

Por isso, a apropriação e o desenvolvimento das máximas qualidades humanas são uma possibilidade para todos desde que encontrem as condiçôes adequadas de vida e educação. Como afirma Saint-Exupéry (2016), deve haver muitos pequenos Mozarts assassinados por falta de condições adequadas de vida e educação.

Para Vygotsky (2010), o desenvolvimento humano na infância ocorre em condições de interação muito especiais de convivência das formas iniciais com as formas finais - mais elaboradas — da cultura que 
servem como guia nesse processo da apropriação progressiva que a criança faz da cultura. Tal convivência pode ampliar sempre a forma inicial e elementar de objetivação aos padróes mais elaborados. Nesse sentido, concebemos a escola como lugar da cultura mais elaborada (MELLO; FARIAS, 2010) e, ao promover a aprendizagem da música, buscamos a produção de um conhecimento escolar que vá para além do cotidiano e do senso comum, que possibilite aos alunos o pleno desenvolvimento humano.

\section{EDUCANDO MUSICALMENTE PARA HUMANIZAR}

Considerando a discussão anterior, entendemos que uma proposta didática de intervenção educativa deve relacionar-se com os alunos como sujeitos criativos e participativos, capazes de dar sentido às suas expressóes sonoras, como pintores descobrindo novas possibilidades de cores e formas. Para isso, deve orientar-se para criar nos alunos um motivo para a açáo, para que a sua participação criadora se configure como uma atividade no sentido histórico-cultural. Com esse olhar, desenvolvemos atividades voltadas para uma escuta mais refinada, mais ativa e que, ao final, se fizesse também criadora.

A escola em que as atividades aconteceram participa do Programa de Educação em Tempo Integral, projeto da Secretaria de Educação do governo do estado de Minas Gerais (PROETI), que busca proporcionar atividades educativas em horário de contra turno para crianças em situação de vulnerabilidade social.

O projeto de educação musical ${ }^{1}$ desenvolvido no âmbito do PROETI envolveu crianças que tinham entre 7 e 12 anos, divididos em duas turmas de 25 participantes: uma turma pela manhã e outra à tarde. O projeto teve a duração de um ano letivo e a intervenção aqui analisada ocorreu entre os meses de agosto e outubro de 2016. O projeto teve como objetivo proporcionar atividades que favorecessem a escuta e a apreciação musical e que, por meio da experimentação e da improvisação musical, os alunos pudessem se perceber como seres criadores, constituindo para si a capacidade de organizar os sons e silêncios e pensar musicalmente esses elementos para construir "conhecimento em contextos significativos, que 
incluam criação, elaboração de hipóteses, descobertas, questionamentos, experimentos" (BRITO, 2003, p. 45).

O trabalho começou com o acolhimento, a escuta e a ampliação da experiência musical dos alunos, quando conhecemos suas preferências musicais e anunciamos uma perspectiva de horizontalidade nas relaçóes entre professora e alunos, de respeito às suas histórias, de acolhimento às suas iniciativas e de compromisso com o trabalho escolar de ampliação de suas vivências.

Segundo Vygotsky (1999), Tolstói não desprezava a experiência que seus alunos traziam para a escola. Ao contrário, acolhia a forma de expressão das crianças, e isso não o impedia de apresentar-lhes novas possibilidades de produção de textos, de livros e de poesias. Entendemos que assim deveria ser a educação musical na escola em uma perspectiva humanizadora: apresentar aos alunos novas possibilidades de escuta musical e ajudá-los na descoberta de formas expressivas de criação sonora.

À medida que conhecíamos suas preferências também fomos apresentando sons de diferentes culturas e diferentes tempos. O que inicialmente causou certo estranhamento, aos poucos criou uma atitude de curiosidade e escuta. Se nas primeiras atividades percebemos que o funk é parte significativa do repertório musical das crianças, nas atividades seguintes os alunos foram incentivados a desenvolver novas escutas e experiências sonoras. Isso ocorreu com jogos de memória auditiva; atividades comparativas de som e imagem para identificar sons graves, agudos e médios; apresentação dos diferentes sons de instrumentos musicais; e apreciação de estilos musicais diversos como a música instrumental clássica, o hip hop, o samba e a ópera.

No início da experimentação musical ativa, passamos à escuta de ruídos produzidos por diferentes objetos - papel, plástico, garrafas de plástico e de vidro de diversos tamanhos, tampas de plástico e de metal, toquinhos de madeira, chapas de raio $\mathrm{X}$, tubos de papelão - e os alunos puderam elaborar estratégias para classificar esses sons, percebendo as diferentes características de cada ruído produzido. No início os alunos classificavam por tipo de material e tamanho, como caixas de tubos de papeláo. Posteriormente, com a ajuda da professora, eles começaram a perceber e questionar sobre as diferenças de timbre entre os tubos de pa- 
pelão quando soprados ou acoplados a uma bexiga, o que posteriormente os ajudou na produção de um instrumento musical próprio: o "bexigofone". Em seguida, vieram os exercícios de escuta de ruídos e sons diversos em gravaçóes, as saídas da sala de aula para observar a paisagem sonora do espaço escolar e experimentar com esses sons.

Aprender a escutar é essencial para uma educação musical humanizadora, pois quando "tomamos consciência do fato sonoro" (BRITO, 2003, p. 187), passamos a interagir com os sons que nos rodeiam e percebemos as pessoas à nossa volta, compreendemos melhor o outro e o mundo em que vivemos. Com a escuta, os alunos puderam perceber que a criação musical demanda ação e interação com as sonoridades à nossa volta, que é preciso tomar consciência dos sons e tentar identificá-los, não os tomando como naturais, mas buscando formas de moldá-los, transformando-os em matéria para a composição musical. Foram percebendo que ao nosso redor existem elementos novos que não percebemos e precisamos conhecer, e se não percebemos é porque os tomamos como naturais. E, para a criaçáo, necessitamos do novo, mesmo que parte do cotidiano, mas que passe a ser percebido com um novo olhar.

Olhar o mundo que nos rodeia e escutá-lo foi o elemento principal da ação imaginativa e criadora desenvolvida. Conforme Vygotsky (2014, p. 88):

O anseio para a ação, representação e concretização, está presente no próprio processo da imaginação [...]. A criança que pela primeira vez vê o trem, dramatiza a sua representação, brinca que é uma locomotiva, bate, apita, tentando imitar o que viu, e experimenta uma grande satisfação em fazê-lo.

A imaginação criativa foi um aspecto importante explorado no processo de ensino e no momento da apresentação dos novos conteúdos, considerando que o ser humano não nasce criativo, mas torna-se criativo à medida que novas possibilidades lhe são apresentadas.

No desenvolvimento da atividade, propusemos uma dramatização com elementos sonoros. Foi uma experiência musical e teatral 
marcada por momentos de experimentação e improvisação, que levou a outras açóes como a decoração do cenário da peça, a inserção de diálogo entre os personagens e a transformaçóes no roteiro: uma profusão de novas ideias e de experimentação para solucionar problemas criados à medida que as mudanças no texto eram assumidas. Nesse processo, vimos acontecer o que Poddiákov (1987) chama de autodesenvolvimento do pensamento, quando, a partir do que é conhecido, os alunos caminham em direção ao desconhecido, num caminho contrário à escola, em que o processo vivenciado pelos alunos tende a ser do desconhecido - apresentado e dirigido pelo professor - ao conhecimento. Nessa organização tradicional do ensino, os alunos esperam do professor o conhecimento pronto para ser assimilado. $\mathrm{Na}$ condiçáo criada em nossa experiência, os alunos passaram a sujeitos criadores, tomando iniciativas geradas por sua possibilidade de pensar a organização do trabalho no grupo.

A experiência criativa coletiva e individual respeitou o desenvolvimento musical do aluno, valorizando suas iniciativas e sua participação. Isso não significou que a professora assumisse o papel de observadora; ao contrário, a interação e a intervenção como organizadora do processo pedagógico e responsável por apresentar elementos que contribuíssem para a ampliação das vivências dos alunos foram parte do processo.

$\mathrm{Na}$ sonorização da peça, os alunos trabalharam em grupo: manipulavam os sons que produziam, discutiam e decidiam coletivamente como e quando deveriam inserir sons no espetáculo. Tal participação e envolvimento criaram condiçóes para os alunos constituírem-se sujeitos de sua própria formação. Assim foram se apropriando do conhecimento e construindo sua visão de mundo, sendo transformados por meio dessa nova relação com o conhecimento e com os outros. Como afirma El'konin (apud REPKIN, 2014), o que distingue o estudo de qualquer outro tipo de atividade é o fato de que seu objetivo e resultado imprimem uma mudança no próprio sujeito da atividade e náo no objeto com o qual o sujeito opera.

A atividade de sonorização da peça teatral expôs o trabalho coletivo como uma forma de expressão do aprendizado e do processo de humanização vivido pelos alunos. Coletivamente, durante as aulas, eles escreveram, modificaram o texto, definiram a ordem das cenas e traduziram em sons as paisagens descritas na história, modificaram es- 
teticamente a forma textual demonstrando um elaborado processo de escuta, de reflexão, de pensamento, de criação. Posteriormente, as crianças se organizaram por grupos de interesses: alguns ficaram encarregados de organizar o cenário e os outros a sonorização. Ainda que planejadas, as intervenções sonoras eram modificadas e enriquecidas no processo de sua elaboração, uma vez que a proposta de ampliação da experiência estética dos alunos em diálogo com sua experiência sonora acumulada e com a cultura mais elaboradas está no cerne do processo de humanização.

Aqui, a imaginação começa a se transformar em objeto da aprendizagem: o vento, o carro, o trováo, o trem, a chuva, tudo sendo concretizado em som. O envolvimento foi além da preparação da sonoplastia: o figurino, a definição dos objetos no cenário, a luz, os tempos... Cada elemento assumiu um sentido no que estava sendo construído pelo grupo. E o processo de criação foi aos poucos tomando forma.

$\mathrm{O}$ valor do trabalho não esteve no resultado final, mas no processo que resultou na peça. Conforme Vygotsky (2014, p. 90), “a criatividade infantil consiste em que seu valor náo reside no resultado, no produto da criação, mas no próprio processo". Por desejo de aparecer em cena, introduziram uma inovação: a produção dos efeitos sonoros da peça foi inserida no cenário. $\mathrm{O}$ trabalho, aos poucos, tornou-se autoral, o que buscamos valorizar no processo de educação musical.

Numa segunda atividade interventiva, iniciamos uma exploraçáo sonora com balóes de aniversário, com o objetivo de aprofundar a escuta ativa. $\mathrm{O}$ fato de ouvir não significa que desenvolvemos o pensamento analítico sobre essa audição. Quando conseguimos descrever as características de um determinado som, pensamos sobre ele e essa capacidade de percepção sonora é o que teóricos da educação musical como Paynter (1972) e Schaffer (1991) chamam de "escuta ativa".

Ao propor a exploração das possibilidades sonoras com balóes de aniversário, desafiamos os alunos a perceber e descrever o tipo de som que ouviam e perceber que o fato de mudarem a forma como "tocavam" o balão influenciava a qualidade sonora produzida: bater o balão na mão produz um som diferente de quando o "raspamos" com dois dedos. Quando foram capazes de definir os elementos sonoros existentes no objeto produtor do som e foram capazes de criar ritmos usando o objeto, perceberam seu domínio sobre a açáo e sobre o instrumento. Nesse pro- 
cesso, percebemos que o trabalho com a educação musical criava nos alunos uma nova atividade e, a partir daí, passaram a ocupar um novo lugar na relação educativa.

$\mathrm{Na}$ dinâmica da apropriação e objetivação, os alunos foram se inserindo na cultura musical e, nesse sentido, a educação musical na escola contribuiu para seu processo de humanização.

Por sua capacidade de influenciar o grupo, de conduzir as açóes e de organizar os colegas para a atividade coletiva, alguns alunos foram escolhidos pelos colegas para dirigir a "orquestra", o que percebemos como uma nova atitude de grupo dos alunos, não mais competindo entre si, mas agindo no coletivo a partir de uma compreensão e um comprometimento com o grupo. O trabalho com a música contribuía, portanto, náo apenas para despertar o interesse dos alunos pela experimentação e pela descoberta com os sons, mas também para seu fazer criativo e para mudanças qualitativas no desenvolvimento de um pensamento mais elaborado. A "orquestra de balóes" foi a realização concreta de uma aula de música quando elementos estruturantes da produção musical — a criação e a reprodução - se apresentaram de forma bem definida. A organização sonora e a capacidade de distinguir as diferentes nuanças dos sons produzidos por uma mesma matéria (balóes de borracha) apontam uma abrangência da educação musical que está além da imitação. Ao mesmo tempo, representaram para os alunos a constituição de uma capacidade sofisticada de concentração, autocontrole, sensibilidade e percepção auditiva, necessárias para a fruição e a produção musical.

Participando do processo e, por isso, compreendendo a atividade como uma necessidade, os alunos passaram a agir movidos pelo prazer de aprender e de criar com o que aprendiam. A nova condição de acolher suas iniciativas — dar voz e vez aos alunos — possibilitou-lhes espaço para a imaginação. Um diferencial importante destacado por Vygotsky é que a imaginação, em tais situaçóes, se transforma em meio para "ampliar as experiências do homem" (VYGOTSKY, 2014, p. 15). Segundo o autor, é dessa forma que o ser humano pode imaginar na narrativa de outros aquilo que náo viu.

Pela lei genética geral do desenvolvimento humano (VYGOTSKY, 1996), aprendemos que as linguagens se constituem para a pessoa nas relaçóes sociais e que mudam de qualidade ao serem 
internalizadas: se desenvolvem em um constante processo de apropriação e objetivação. Nessa perspectiva, a linguagem musical, como elemento do desenvolvimento humano inicialmente externo aos alunos, transformou-se qualitativamente em elemento mediador interno do processo de seu conhecimento que, com eles, se apropria do conhecimento e o objetiva não apenas na educação musical, mas como um conjunto de novas possibilidades. Em outras palavras, o conjunto de novas ações realizadas não foi um simples movimento externo, foi interno. Essa capacidade imaginativa que conduz o ser humano para a criatividade é também condição necessária para desenvolver atividades intelectuais que têm como base também a autoestima positiva que vimos formar-se nos alunos.

\section{BREVES CONSIDERAÇÕES}

Com a abordagem histórico-cultural do desenvolvimento humano, aprendemos que as condiçóes materiais de vida e educação - o que envolve a concepção de criança, de aluno, de escola, de educação, de processo de conhecimento, bem como suas implicaçóes para a organização do ambiente escolar - constituem a base para a formação da inteligência e da personalidade. Nesse sentido, a criação dessas condiçóes materiais favoráveis na escola foi o primeiro passo rumo à condução de um processo educativo que buscou privilegiar a autopercepção dos alunos como seres criativos. Ao respeitar primeiramente e buscar conhecer seu gosto musical, procuramos manter um diálogo compreensível, respeitando-os como pessoa. A partir daí, buscamos apresentar outras formas e estilos de música que aos poucos foram despertando a curiosidade do grupo. Entendemos que aí começamos a encontrar meios para despertar sua atenção para o novo e para constituir uma nova sensibilidade e que a escola tem um papel essencial nesse despertar do aluno para fruir das objetivaçóes da esfera superior da atividade humana como a arte. Mais que fruir da música, procuramos provocar os alunos para experimentar novas possibilidades sonoras e musicais, para criar sua própria estrutura e estilo musical, para se perceber sujeito de sua ação no mundo. Como afirma Vygotsky, "a arte é um enfoque emocional original e predominantemente... dialético da construção da vida” (VYGOTSKY, 1999, p. 328). 
Compreender que o ser humano é um ser social, e que todas as relaçóes que envolvem o aprendizado e o seu desenvolvimento resultam das relaçóes que se desenvolvem socialmente parece ser o caminho mais adequado para entender a educação musical na escola fundamental. Buscar meios de apresentar esses conhecimentos de modo desenvolvente foi o desafio que procuramos enfrentar, entendendo que o aluno em contato com uma educaçáo musical genuína voltada para o desenvolvimento da escuta e da experimentação tem mais oportunidade de acolher atividades que estimulem e despertem nele o desejo e a necessidade do fazer criativo.

\section{REFERÊNCIAS}

BRITO, T.A. de. Música na educação infantil. São Paulo: Peirópolis, 2003.

DAVÍDOV, V.V. La enseñanza escolar y el desarrollo psíquico: investigación teórica y experimental. Tradução de M. Shuare. Moscou: Progresso, 1988.

LEONTIEV, A. Actividad, conciencia y personalidad. Buenos Aires: Ediciones Ciencias del Hombre, 1978a.

. O desenvolvimento do psiquismo. Lisboa: Livros Horizonte, 1978b.

MELLO, S.A.; FARIAS, M.A.S. A escola como lugar da cultura mais elaborada. Educação, v. 35, n. 1, jan.-abr. 2010. http://dx.doi.org/10.5902/198464441603

PAYNTER, J. Oir, aqui y ahora: una introducción a la música actual em las escuelas. Buenos Aires: Ricordi Americana, 1972.

PODDIÁKOV, N. Sobre el problema del desarrollo del pensamiento en los preescolares. In: DAVÍDOV, V.V.; SHUARE, M. (Orgs.). La psicología evolutiva y pedagógica en la URSS. Moscou: Progresso, 1987.

REPKIN, V.V. Ensino desenvolvente e atividade de estudo. Ensino em Re-Vista, v. 21, n. 1, p. 85-99, jan./jun. 2014.

SAINT-EXUPÉRY, Antoine. Terre des Hommes. Tradução de Rogério Barbosa Lima. Revista Cátedra Digital, v. 2, 2016.

SCHAFFER, R.M. O ouvido pensante. São Paulo: Editora da UNESP, 1991.

VYGOTSKY, L.S. Imaginação e criatividade na infância. São Paulo: WMF/ Martins Fontes, 2014.

. Obras escogidas. Madri: Visor, 1996. v. 4. 
Psicologia da Arte. Tradução de Paulo Bezerra. São Paulo: Martins Fontes, 1999.

- Quarta aula: a questáo do meio na pedologia, Lev Semionovich Vigostki. Psicologia USP, São Paulo, v. 21, n. 4, p. 681-701, 2010. https://doi. org/10.1590/S0103-65642010000400003

\section{NOTA}

1. Pesquisa aprovada pelo Conselho de Ética em Pesquisa (CEP)/Conselho Nacional de Ética em Pesquisa (CONEP), protocolo no CAAE 51448215.9.00005142.

Recebido em 24 de agosto de 2018.

Aprovado em 11 dezembro de 2018. 